\title{
Words of Wisdom
}

\author{
Madan Kapre \\ Neeti Nursing Home, 21, Central Bazar Road \\ Ramdaspeth, NAGPUR-440010.
}

\section{||||||||||||||||||||||||||||||||||||||||||||||||||||||||||||||||||||$|+||||||||||||||||||||||||||||||||||||||||||| \mid$}

C ontinuing from where it was left at the A.O.I. Golden Jubilee Conference at New Delhi it is endeavoured to tackle this subject further for the benefit of readership of our journal. Attempt is made to find practical solutions to the problems faced by both old and new apprentices in our fold during their career. We are all taught through post-graduate teaching, workshop, CME about surgical techniques. We are also taught about voluminous research and theories that go with it. What we are not taught and we toil and sweat to learn it the hard way is "Words of Wisdom".

A practical situation is created where in there could be problems of ethics, education, research, surgical failures and so on. We have seaked for this column "Words of Wisdom" help from luminaries from various sections of our seniors with years of experience in teaching and non-teaching institutions. We have then put forth some views on the issue. As this is the beginning of a new column we earnestly request our readership to participate and enable us to enter into a territory which had been considered as taboo. High in roads could be made for the smooth sailing of our juniors in these hostile tẹrain of clinical practice where angels fear to trade.

Clinical situation with ethical dialema is created thus.

At the end of routine consultation, you have advised surgical treatment to your patient. At this point of time your patient produced pa- pers of earlier consultations which have advised against such surgical treatment.

$=$ Other consultant is senior to you.

$=$ Other consultant is junior to you.

$=$ Other consultant is unknown to you.

= May be there is totally different working/institutional infrastructural back up.

How do you cope with this?

It has been my experience that patients coming to me now are for second opinion or revision surgery if necessary. My opinion for surgery is based on detailed clinical history coraborated on critical evaluation of routine and special investigations relavent to the case which is either chronic disease or malignancy. My advice for surgery is from multi disciplinary point of view with infrastructural set up and technological back up followed by me.

It has been my practice to discuss about the disease with the patient and his relatives and clarify all their queries and doubts. The other modalities of management if are prolonged, likely to exacerbate and without any guarantee of cure it would be prudent to opt for surgery if it is safe. It avoids uncertainty, mental tension and is cost effective in the long run. Safety of the operation and cost factor are important factors from patient's point of view.

My advice for or against surgery would not be influenced by previous opinion of my colleagues either senior, junior or unknown to me. 


\section{N.K.Apte- Mumbai}

The problem situation that you have posed is, unfortunately, not too uncommon in my practice.

My approach to this situation is fairly straight forward. I tell the patient that it is possible for different surgeons to have more than one approach to treating a problem and that my approach in this particular instance would be surgical. I would also say, that, this is the approach that has worked in my hands and the ball was now in the patient's court and that it was upto him to decide whose recommendation he has to follow.

It is however, worth bearing one or two points in mind. The very fact that this patient has gone "shopping" all over the place and has hidden his previous consultations from me would indicate, that this person is less than forthright. I would be wary of this person.

\section{Mohan Kameswaran-Chennai}

My answer will be same in all situations whether the earlier consultant is senior, junior, or unknown to me.

I will explain the patient that I have examined you: today and as per clinical findings you need a surgical treatment. This is my opinion after through study of your problem.

Further I will tell the patient that I would have advised surgery in similar situations even to my close relatives as it is indicated.

I will totally aviod untoward remarks towards our own colleague (Consultant) as clinical findings and situation may be different when he has seen the patient.

\section{V.B.Chitale- Pune}

You may have your own ways of handling this situation. Please interact with us freeiy and encourage us by your active co-operation 'n seeking and spreading "Words of Wistom". $t$ is not infrequent happening that small inno cent looking central tympanic perforation refuses to close event after meticulous surgical repair. Occasionally much to the dismay of the operator it actually gets bigger than before. Senior Surgeon who had faced this rough sea and younger surgeons who have sailed into surgical careers recently were requested to share their views and their actual patient management on this rather embarrasing problem. Emphasis was requested more on following points.

- What do you actually say about the failure of surgical procedure?

- When do you operate?

- Any change in your operative technique?

- Charges for the second surgical procedure, if it is private institution?

- How do you explain if the earlier surgeon was other than yourself?

I have compiled their answers as close to what they have to contribute for the benefit of readership. I hope these words of wisdom will prove useful and console the younger aspirants of our fold.

Failures are substantially more in people above 30 years of age than in younger patients. Status of middle ear mucosa affects our results. Many of them are not, "Permanent perforation syndrome" but, "persistant mucosal disease" which always gives poorer results.

Now about specific questions you have asked: always explain preopratively that the graft is a free graft without any attached source of blood supply. [Explained in words patient will understand and it can fail in a fair no of cases. I tell the patient frankely about any residual perforation / which is more frequent than total failures] or about failures when I am satisfied that it will not heal usually after 3 months.

I wait for atleast one year before reoperation. In a large number of cases apparent failures heal completely |Even subtotal perforations| if enough time is allowed to lapse. If it is moder- 
ate or small perforation, I always do T.C.A. cautery and wait long enough after that before fresh operation is advised.

For second operation there is basically no change in operative technique. It is a known fact that a healed wound reopened heals more quickly. Site of harvesting graft changes. II always use temporalis tascia onlyl.

Even a simplified inlay in a failure, heals very well the second time, Percentage of failures second time are surprisingly very low.

I have never charged any of my patients for reoperation. But I explainto them and always collect actual expenditure-including anaesthetists charges etc.,

If a colleague's failure comes to me. I treat it exactly as above. It is better to casually mention that failures can occur even in the best hands without over emphasizing failures.

\section{S.R. Pande. Nagpur}

At the time of consultation when I realise that there is possibility of residual perforation and need for revision. I inform the patient of failure of surgery.

I discuss the "WHY" of reperforation based on following points.

\section{[II]}

- Total perforation: Chances are higher for reperforation [also told preoperatively]

- Nasal/sinus infection in 2-3 weeks postoperatively.

- I always discuss failure with my colleague going over details as it gives a fresh independent view.

- There is no gross deviation from the original technique except if temporalis fascia is not adequately

available, the tragal perichondrium may be harvested as graft material.

- Patient pay for anaesthetist and drugs but no surgeon charges, in revision surgery.

- I ask for operation notes from patient and details of operation and post operative events which may

help know the cause, investigate the patient thoroughly, including sinuses.

- Operative technique is same, if I was not the original surgeon.

- I also tell the possibility of failure again.

- I do not discuss about surgeon in question.

\section{A.D. Deshmukh. Mansfield [U.K.]}

[III]

Residual perforation in the tympanic membrane after tympanoplasty procedure occurs due to 2 reasons, mainly-faulty technique or prevalence of the causes which caused the perforation specially when we operate in the quiescent phase of the disease. In the initial postoperative period conservative techniques like suction-lifting of medialised graft, chemical cautery should be tried. If these fail and the perforation persists, if should be brought to the patients notice immediately while we are doing the conservative measures.

Recurrence of a perforation can occur after complete healing of the tympanic membrane has occured during ensuring few months. We should tell our patient that when we do an eardrum repair operation, we are treating the effect of CSOM, however the causes like allergy, eaustachian tube dysfunction still remain and these are difficult to treat.

My further management of both the above conditions would depend on the size of the perforation, the quality and the quantity of the hearing loss, age of the patient, patients demanding and ready for second operation.

I would like to rule out all the possible causes/ conditions which could directly or indirectly effect final outcome of the operation specially in the upper and lower respiratory tract. A proper audiological testing supported by a thorough clinical examination is of paramount importance. Consent for the revision on warrants a special mention.

Intraoperative technique would defer from the 
previous operation in the following steps:-

- Strictly a postaural approach.

- Cartilage with perichondrium ITragal/ chonchal] as graft material.

- Cortical mastoidectomy with near complete exenteration of all mastoid air cells, coupled with widening of the aditus and achieving a good exposure of the attic through the mastoid. These measures would fecilitate in achieving a satisfactory atticoantral patency and thereby postoperative aeration of the middle ear.

- Flushing of eustachian tube with normal saline.
Following measures would be done in selected cases:

- Canal plasty with meatoplasty.

- Ossiculoplasty.

- Thicker composite graft material in associated prebycusis where postoperatively hearing-aid is advised.

I would impress upon him that such failures would occur with the best of the surgeons. I would never doubt.

my colleagues proficiency.

Kishore, B. Sandu Mumbai. 